\title{
Quantifying Urban Sprawl and Its Driving Forces in China
}

\author{
Jintao Wang, Shiyou Qu, Ke Peng, and Yanchao Feng \\ School of Economics and Management, Harbin Institute of Technology, Harbin 150001, China \\ Correspondence should be addressed to Yanchao Feng; m15002182995@163.com
}

Received 21 January 2019; Accepted 21 April 2019; Published 6 May 2019

Academic Editor: Maria Alessandra Ragusa

Copyright (C) 2019 Jintao Wang et al. This is an open access article distributed under the Creative Commons Attribution License, which permits unrestricted use, distribution, and reproduction in any medium, provided the original work is properly cited.

\begin{abstract}
Against the background that urbanization has proceeded quickly in China over the last two decades, a limited number of empirical researches have been performed for analyzing the measurement and driving forces of urban sprawl at the national and regional level. The article aims at using remote sensing derived data and administrative data (for statistical purposes) to investigate the development status of urban sprawl together with its driving forces. Compared with existing studies, NPP/VIIRS data and LandScan data were used here to examine urban sprawl from two different perspectives: urban population sprawl and urban land sprawl. Furthermore, we used population density as a counter-indicator of urban sprawl, and the regression results also prove the superiority of the urban sprawl designed by us. The main results show that the intensity of urban population sprawl and urban land sprawl has been enhanced. However, the upside-down between the inflow of migrants and the supply of urban construction land among different regions aggravates the intensity of urban sprawl. According to the regression analyses, the driving mechanism of urban sprawl in the eastern region relying on land finance and financial development has lost momentum for the limitation of urban construction land supply. The continuous outflow of population and loosely land supply have accelerated the intensity of urban land sprawl in the central and western regions. The findings of the article may help people to realize that urban sprawl has become a staggering reality among Chinese cities; thereby urban planners as well as policymakers should make some actions to hinder the urban sprawl.
\end{abstract}

\section{Introduction}

More and more scholars as well as urban planners begin to pay attention to urban sprawl considering its economic, social, and environmental costs and effects [1-8]. In fact, the urban sprawl and land degradation have consequences on biodiversity too, which is highly vulnerable in areas which have cropped up without formal planning [9-11]. Urban sprawl, as a famous American phenomenon originally, is mainly characterized by low-density development, leapfrog, and scattered development, as well as poor accessibility in comparison to compact development [12]. However, since urban sprawl becomes serious resulting from quick urbanization as well as urban expansion in city fringes and the edge of metropolitan areas, the study of the measurement of urban sprawl together with its driving forces in Chinese cities has emerged as a hot topic in recent years [13-22].

Due to the fact that focusing on one obvious dimension is more effective than focusing on multiple indexes during measurement, the measurement of urban sprawl in early time mostly takes into account population density or urban area growth $[1,23]$. However, there is a big deviation between registered population and permanent population since a large amount of people in inland migrates to coastal regions, and it lacks long-term panel data of permanent population in government collected data. The problem of data distortion in the population density calculated by the registered population increases our attention [24]. Furthermore, cities in China greatly suffer illegal or unauthorized development issue, which, however, do not receive enough attention in the data collected by the government [2]. In recent studies about urban sprawl, scholars have adopted a multidimensional measurement method [25]. But no consensus has been reached about which dimension shall be included into the multidimensional measurement about urban sprawl; also, there is no uniformity about using individual dimension or combining dimensions [23]. Fortunately, in recent dozens of years, regarding the spatial analysis on urban sprawl, it has 
been a common method by applying remote sensing derived data to the estimation of urban sprawl because it can accurately reflect the spatial distribution of people's economic, social, and environmental activities compared to government collected data [26-32]. Based on the existing research results, we use remote sensing derived data to calculate the extent of urban population sprawl and urban land sprawl and then square the product of the two. The final result is the index of urban sprawl used in this paper. The temporal and spatial development mode of urban sprawl in single cities have been studied in most researches based on the measurement result of urban sprawl particularly these metropolises in developed eastern coastal areas [13, 33-39]. However, little is known about urban sprawl among different cities throughout China utilizing national datasets; therefore, it is especially necessary to use nationally representative datasets to deeply study urban sprawl in China.

New research suggests that dramatic urban sprawl in China, on the one hand, has been promoted by the market and economic development, just like the US and other countries in the west, and on the other hand is attributable to China's land financing as well as the land-centered urbanization strategies [40-42]. As the rural-to-urban land circulation system is loose in China, a large portion of municipal revenues of local government are obtained via urban sprawl [43]. However, on the background of narrowing the imbalance among different regions, the central government of China keeps requiring local governments to tighten up rural-to-urban land conversion process as well as preserve farmland, which makes the land financing and land-centered urbanization policies lose the advantage [44]. Through the leverage of bank credit, land finance with the core of land mortgage loan has obtained more disposable funds from urban sprawl in China; "growing wealth by land and supporting land by wealth" is a vivid reflection of the driving forces of urban sprawl [45]. Therefore, financial development can also significantly promote the intensity of urban sprawl. However, due to the serious imbalance of regional development, the mechanism of land finance and financial development on urban sprawl has significant spatial heterogeneity among different regions; in-depth studies of the driving forces of urban sprawl using regionally representative datasets are much needed.

Based on the discussion above, previous related literature is insufficient. The paper aims to compare different regions in terms of their sprawl degree, analyze the effects of land finance, financial development, and their interaction on urban sprawl in different regions, and reveal the spatial heterogeneity of land finance, financial development, and their interaction on urban sprawl at the national and regional level. Specifically, using the 2012-2017 remote sensing derived data, urban sprawl was quantified by virtue of two metrics extracted from NPP/VIIRS data and LandScan data, followed by the comparison of different cities in terms of the sprawl degree difference. Furthermore, we compared the spatial heterogeneity of land finance, financial development, and their interaction on urban sprawl based on spatial Durbin model. A qualitative analysis was performed at last on the driving forces of above findings.
This paper falls into five sections. Section 2 involves data and variables, like data source, data extraction process, method to measure urban sprawl, and independent variables. Section 3 presents the spatial Durbin model as well as spatial weight matrix. Section 4 presents the results, including the effects of land finance and financial development on urban sprawl at the national and regional level. Section 5 draws our conclusions and offers some policy implications.

\section{Data and Variables}

There are two levels of Chinese cities based on the administrative level, namely, the prefecture-level cities and the countylevel cities. As regulated by administrative division system, prefecture-level cities include municipal districts, countylevel cities, counties, towns, and other units. In terms of the identification of city, in China, a prefecture-level city usually refers to a municipal district similar to city in western countries [23]. However, there are no clear central urban areas in a county-level city, which, to a large extent, has many nonurbanized areas. On that account, prefecture-level cities were selected as samples in the study. Due to data incompleteness (some regions are excluded provisionally considering the lack of data, such as the Taiwan Area, Macau, and Hong Kong of China; many cities have underwent adjustment about administrative divisions in the past ten years, and some other cities have lost data of certain years), a panel data set of 285 prefecture-level cities in the time range of 2011-2017 has been used as our samples. China's current administrative division criteria divide the samples into three regions, namely, the eastern region, the central region, and the western region (Figure 1).

The study mainly uses four data types, NPP/VIIRS data, LandScan data, administrative boundary data, and administrative statistical data. Our data sources are listed in Table 1 in terms of the format and the source. The Earth Observations Group (EOG) at NOAA/NCEI is producing a version 1 suite of average radiance composite images by virtue of the nighttime data obtained from the Visible Infrared Imaging Radiometer Suite (VIIRS) Day/Night Band (DNB) since April 2012. The version 1 VIIRS DNB Nighttime Lights were available at the official website of NGDC (https://ngdc .noaa.gov/eog/viirs/download_dnb_composites.html). Prior to the averaging, the DNB data affected by lighting, stray light, cloud cover, and lunar illumination have been filtered out. As for the generation of the data, the spatial resolution is 15 arc seconds spanning $-180^{\circ}$ to $180^{\circ}$ in longitude and $65^{\circ}$ to $75^{\circ}$ in latitude. The temporal averaging is calculated by month and year. However, the version 1 series of annual composites has not been announced to the public at present. Furthermore, as version 1 series of monthly composites did not receive filtration treatment for screening out lights from fires, aurora, and boats, as well as other temporal lights, it is necessary to perform further extraction in our research. LandScan of ORNL acts as a community criterion for population distribution data worldwide (available at https://landscan.ornl.gov/landscan-datasets). With spatial resolution of $1 \mathrm{~km}\left(30^{\prime \prime} \mathrm{X} 30^{\prime \prime}\right)$ or so, an ambient population distribution (average over 24 hours) can be displayed in 


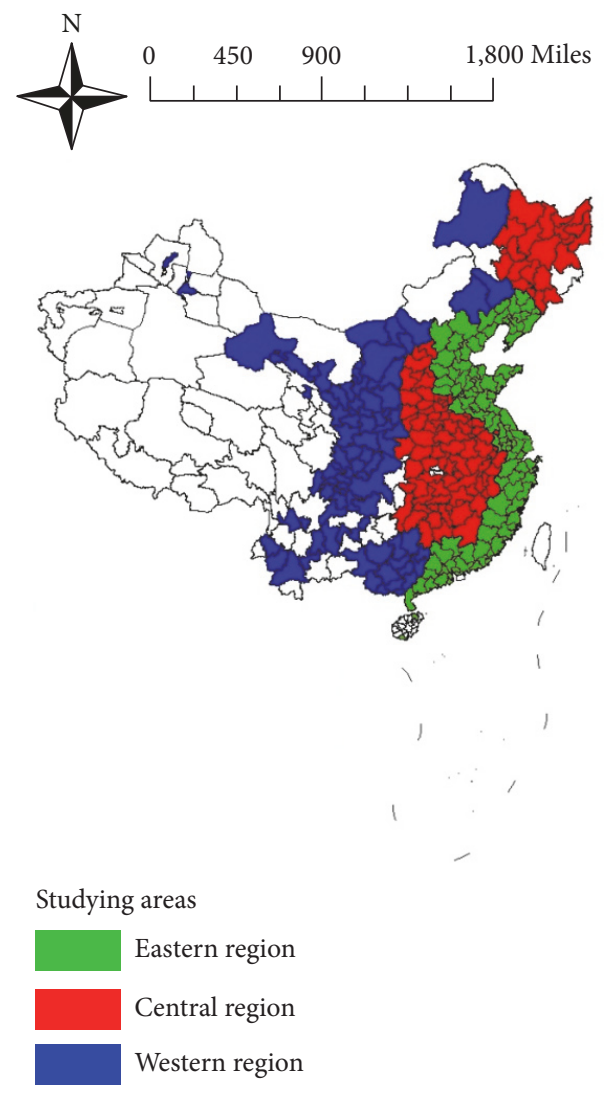

FIGURE 1: Studying areas.

ORNL. Being refreshed each year, it can be released to broader user community at nearly October. Data of administrative boundary were collected from the National Geomatics Center of China (available at http://www.ngcc.cn/). Administrative statistical data were collected from China City Statistical Yearbook, China Urban Construction Statistical Yearbook, and China Land and Resources Almanac; all of the core explanatory variables and control variables used in this paper are selected from these datasets.

2.1. Dependent Variables. The projection of NPP/VIIRS data was carried out through Lambert Azimuthal Equal Area projection and resampling was performed when the spatial resolution was $1 \mathrm{~km}$. By removing noise and averaging the monthly nighttime light data, annual nighttime light data were obtained during 2012-2017. Furthermore, using the annual nighttime light image with an average value of above 10 as a mask, we extracted the area with a population density greater than 1000 person per square kilometer from LandScan data as our research sample.

Population density used to be a counter-indicator of urban sprawl to characterize the degree of population agglomeration. Although this method roughly reflects the general situation of urban sprawl, it is difficult to truly reflect the spatial pattern of a city [23]. We propose the characteristics of urban sprawl from two aspects: urban population sprawl and urban land sprawl [46].

$$
U P S_{i t}=0.5 *\left(L P_{i t}-H P_{i t}\right)+0.5
$$

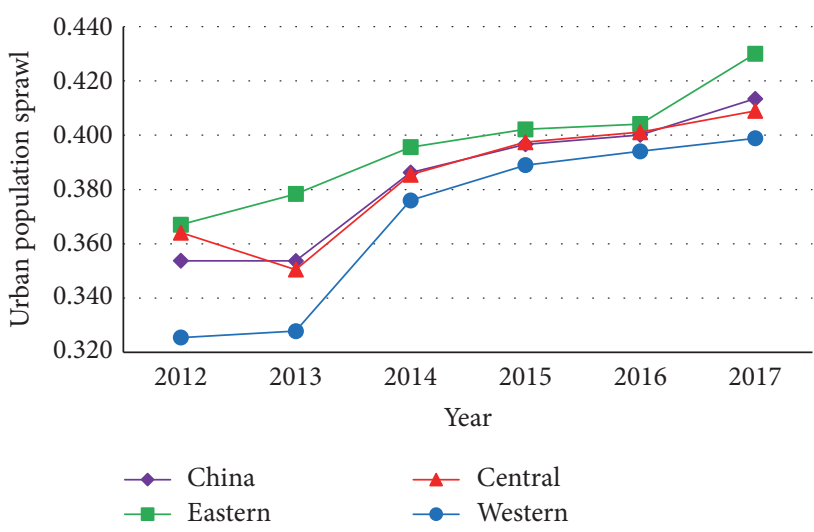

FIGURE 2: Urban population sprawl in China during 2012-2017.

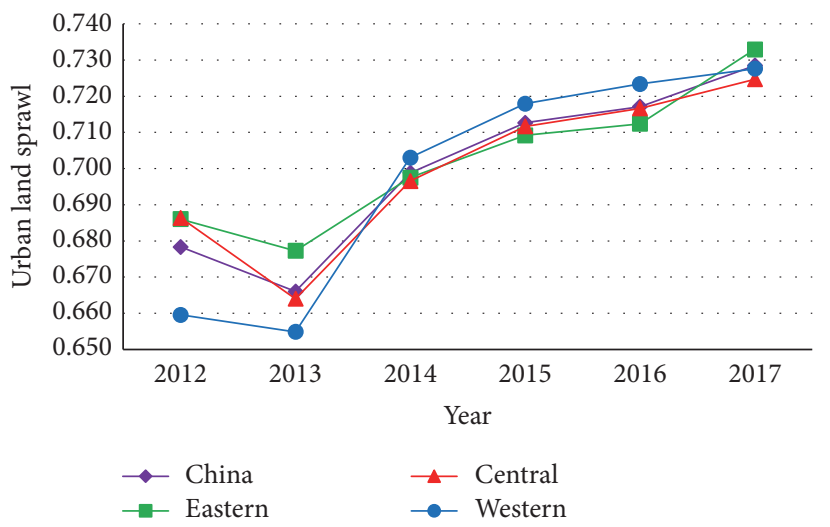

FIGURE 3: Urban land sprawl in China during 2012-2017.

$$
U L S_{i t}=0.5 *\left(L L_{i t}-H L_{i t}\right)+0.5
$$

where $U P S_{\text {it }}$ is the value of urban population sprawl in city $i$ at year $t ; L P_{i t}$ is the proportion of the population with population density below the national average value accounts for total population in city $i$ at year $t ; H P_{i t}$ is the proportion of the population with population density above the national average value accounts for total population in city $i$ at year $t$. Correspondingly, $U L S_{i t}$ is the value of urban land sprawl in city $i$ at year $t ; L L_{i t}$ is the proportion of the land area with population density below the national average value accounts for the total land areas in city $i$ at year $t ; H L_{i t}$ is the proportion of the land area with population density above the national average value accounts for the total land areas in city $i$ at year $t$. These two indicators are ranging from zero to one, and the larger value means the higher sprawl and vice versa.

To illustrate the spatial correlation of urban sprawl in an intuitive way, the urban population sprawl and urban land sprawl of 285 prefecture-level cities are investigated from 2012 to 2017 presented in Figures 2 and 3. There are three main observations. First, there is an imbalance between urban population sprawl and urban land sprawl regarding their growth rate; the growth rate of urban land sprawl has exceeded urban population sprawl at the national and regional level during 2012-2017. Second, we have investigated that the eastern region exhibits a stronger urban population sprawl compared 
TABLE 1: The datasets used in the study (by format and source).

\begin{tabular}{|c|c|c|c|}
\hline Data Type & Year & Format & Data Source \\
\hline NPP/VIIRS data & $2012-2017$ & Geo Tiff & https://ngdc.noaa.gov/eog/viirs/download_dnb_composites.html \\
\hline LandScan data & 2012-2017 & Geo Tiff & https://landscan.ornl.gov/landscan-datasets \\
\hline Administrative boundary data & $2012-2017$ & Shp & https://www.ngcc.cn \\
\hline Administrative statistical data & 2011-2016 & Excel & $\begin{array}{c}\text { China City Statistical Yearbook } \\
\text { China Urban Construction Statistical Yearbook } \\
\text { China Land and Resources Almanac }\end{array}$ \\
\hline
\end{tabular}

with the central and western regions as a larger number of people in the inland migrate to the coastal regions. Third, we investigated urban land sprawl in the central and western region during 2014-2016 surpasses that, in the eastern region, implying that China's national government's inclination is to supply more urban construction land in the central and western regions compared with the eastern region, which contrasts with the strict control of the first-tier cities' land supply in the eastern regions.

Furthermore, we propose a comprehensive index to test the extent of urban sprawl based on the above two equations.

$$
U S_{i t}=\sqrt{U P S_{i t} * U L S_{i t}}
$$

where $U S_{i t}$ is the value of urban sprawl in city $i$ at year $t$. Correspondingly, the value of urban sprawl is ranging from zero to one; the larger value means the higher sprawl, and vice versa.

2.2. Core Explanatory Variables. The tax-sharing reform caused the situation of "relocation of financial power" and "retention of administrative power" in China since 1994 [40]. Moreover, considering China's national government's emphasis on people's livelihood expenditure, the fund supporting mechanism, and the large-scale implementation of the project system, it was difficult for general public budget expenditure to cover large-scale urban infrastructure construction, subsidize industrial land, and investment expenditures like tax reduction, which caused a huge gap between local fiscal revenue and expenditure [41]. In the face of the huge demand for urbanization and the restrictions imposed by the Budget Law on local borrowing, land finance has become the "secondary finance" for local governments [42]. Financial development is one of the important forces for driving urban sprawl by reducing transaction costs, improving allocation efficiency, and optimizing industrial structure [43]. Under the combined effect of limited land supply and rigid housing purchases, house prices have been pushed up [43]. High profits attracted more funds to participate in the competition in the real estate market, which intensified the competition in the commercial and residential land market, thus forming the coexistence of high housing prices and urban sprawl [41]. Also, land finance obtained more disposable funds for local governments from land transfer through the leverage effect of bank credit, which played a role in fueling the formation of land finance [43]. Therefore, we choose land finance and financial development as the core explanatory variables of this paper.
Specifically, this paper chooses the shares of land leasing revenue in GDP as a substitute for land finance; because land leasing revenue belongs to extra-budgetary income or government fund income, local government has more power to control the application of it. Besides, this paper chooses the shares of both deposits and loans in GDP as a substitute for financial development, because the impact of direct financing is more important than securities financing on urban sprawl in China.

2.3. Control Variables. In China, the urban sprawl is also affected by some economic and institutional factors [8-16]. As a result, the econometric estimation includes six control variables: (1) human capital (HC), i.e., the number of college students per 10,000 people; (2) gross domestic product (GDP), i.e., per capita GDP; (3)fiscal expenditure (FE), i.e., per capita fiscal expenditure; (4) education expenditure (EDU), i.e., per capita education expenditure; (5) hospital condition (HOS), i.e., number of beds in hospital per 10,000 people; (6) green degree (GD), i.e., green area coverage in built-up areas.

Taking the year of 2011 as the base period, we process the economic variables at a constant price, aiming at eliminating the influence of price fluctuations, while all variables have received logarithmic treatment for eliminating the influence brought by heteroscedasticity. Specifically, considering the time lag of impacts, all independent variables are processed in a one-stage lag. Table 2 reports the descriptive statistics of relevant variables which were used in the paper.

\section{Methodology}

3.1. Spatial Durbin Model. The spatial econometrics theory states that a regional space unit in a certain economic geography phenomenon or certain attribute values is significantly related to a neighborhood space unit [47]. The estimated result of the OLS estimation, which makes an assumption that observations are not spatially correlated, will be a biased and nonconsistent estimation of parameter [48]. A spatial econometric model shall be built for getting accurate estimation results. Therefore, we construct a spatial Durbin model (SDM) to consider the impacts of land finance, financial development, and their interaction on urban sprawl in China. The common SDM can be expressed as

$$
y=\rho W y+X \beta+W X \theta+\alpha+\mu
$$

where $W$ denotes the nonnegative $N \times N$ spatial weight matrix, which reflects the interdependent space relation 


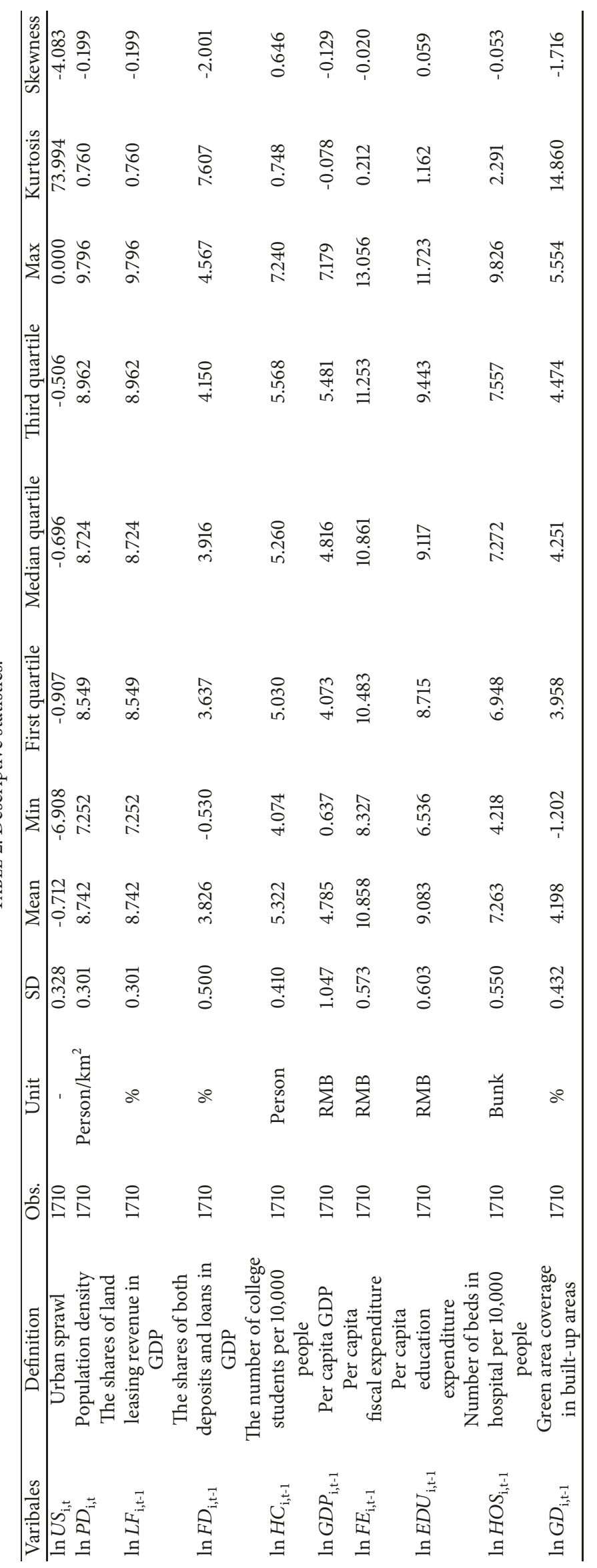


between different cross-sections. $W y$ and $W X$ are the spatial lag terms of the dependent variables and independent variables, respectively. Relying on such kind of spatial lag terms, the spillover effects of neighboring cities on certain city can be analyzed.

SDM takes into accounts the impacts of both the spatial lag dependent variable and the spatial lag independent variable. Based on certain assumption, SDM can be reduced to two modes, spatial lag model (SLM) and spatial error model (SEM). From (4), two assumptions were considered: (i) $H_{0}^{1}$ : $\theta=0$ and (ii) $H_{0}^{2}: \theta+\beta \rho=0$. If $H_{0}^{1}$ holds, the SDM can be reduced to a SLM; while if $H_{0}^{2}$ holds, SDM can be reduced to a SEM; when both conditions hold, it can equal to a nonspatial panel model $[48,49]$. Therefore, compared to other spatial models, the SDM is a more generalized form. However, for making sure the applicability of SDM to certain regression analyses, it is necessary to perform relevant statistical tests, and the Wald and likelihood ratio (LR) test shall be carried out for confirming if the SDM can be reduced to a SLM or SEM [50]. The Hausman test helps the study to confirm that which effect is adopted by the spatial econometric model, fixed effect or random effect [51].

It is impossible for the independent variable coefficients in the regression model to make an accurate reflection about the margin effect as the spatial panel model exhibits spatial correlation. There are two types of marginal effect, namely, direct effect and indirect effect. The two types of margin effect can be employed to explain the model about its information. The SDM can be transferred as follows:

$$
y=(I-\rho W)^{-1}(X \beta+W X \theta+\alpha+\mu)
$$

where $I$ is an $\mathrm{N} \times 1$ unit matrix and $\mathrm{N}$ is the quantity of cities. The spatial Leontief inverse matrix can be expanded into following formula:

$$
(I-\rho W)^{-1}=I+\rho W+\rho^{2} W^{2}+\cdots
$$

The $1^{\text {st }}$ term of the right equation (5) refers to the direct effect, and the remaining part stands for the indirect effect [52]. The $1^{\text {st }}$ partial derivative of dependent variables to independent variables is expressed as

$$
\begin{aligned}
\frac{\partial y_{i}}{\partial x_{i r}} & =S_{r}(W)_{i i} \quad \text { for all } i \text { and } r \\
\frac{\partial y_{i}}{\partial x_{j r}} & =S_{r}(W)_{i j} \quad \text { for all } i \neq j \text { and for all } r \\
S_{r}(W) & =\left(I_{N}-\rho W\right)^{-1}\left(I_{N} \beta_{r}-w_{r} W\right)
\end{aligned}
$$

where $\beta_{r}$ is the coefficient of the $r$ th independent variable and $w_{r}$ is the coefficient of the spatial lag term of the $r$ th independent variable. $S_{r}(W)_{i i}$ stands for the element in the diagonal line, which indicates how the independent variable affects the dependent variable in the $i$ th city, i.e., the direct effect. That is to say, simply averaging the elements in the diagonal line can get the average direct effect. The offdiagonal elements reflect how the independent variable of the $j$ th city affects the dependent variable of the $i$ th city, i.e., the indirect effect or spillover effect. That is to say, simply averaging all the off-diagonal elements can get the average indirect effect. Summing up average direct effect and indirect effect can obtain the average total effect and also the average of all the elements.

From above analyses, the following SDM is applied to studying land finance and financial development as well as the spillover effects on urban sprawl:

$$
\begin{aligned}
\ln U S_{i, t}= & \rho \sum_{j=1}^{N} W_{i j} \ln U S_{j, t}+\beta_{1} \ln L F_{i, t-1} \\
& +\beta_{2} \ln F D_{i, t-1}+\beta_{3} \ln L F_{i, t-1} * \ln F D_{i, t-1} \\
& +\theta_{1} \sum_{j=1}^{N} W_{i j} L F_{i, t-1}+\theta_{2} \sum_{j=1}^{N} W_{i j} \ln F D_{i, t-1} \\
& +\theta_{3} \sum_{j=1}^{N} W_{i j} \ln L F_{i, t-1} * \ln F D_{i, t-1}+X_{i, t-1} \gamma \\
& +\varphi \sum_{j=1}^{N} W_{i j} X_{j, t-1}+\alpha_{i}+\mu_{i, t-1}
\end{aligned}
$$

In order to contrast with urban sprawl, we also use population density (PD) greater than 1000 extracted from LandScan data as a counter-indicator.

$$
\begin{aligned}
\ln P D_{i, t}= & \rho \sum_{j=1}^{N} W_{i j} \ln P D_{j, t}+\beta_{1} \ln L F_{i, t-1} \\
& +\beta_{2} \ln F D_{i, t-1}+\beta_{3} \ln L F_{i, t-1} * \ln F D_{i, t-1} \\
& +\theta_{1} \sum_{j=1}^{N} W_{i j} L F_{i, t-1}+\theta_{2} \sum_{j=1}^{N} W_{i j} \ln F D_{i, t-1} \\
& +\theta_{3} \sum_{j=1}^{N} W_{i j} \ln L F_{i, t-1} * \ln F D_{i, t-1}+X_{i, t-1} \gamma \\
& +\varphi \sum_{j=1}^{N} W_{i j} X_{j, t-1}+\alpha_{i}+\mu_{i, t-1}
\end{aligned}
$$

The most likelihood estimation (MLE) method is applied to the estimation of (10) and (11).

3.2. Spatial Weight Matrix. Different from the OLS estimation, spatial econometric method introduces spatial weight matrix [49], which can be constructed following two standards, namely, the neighboring standard and the distance standard. The paper mainly considers nonbordering regions which approach to the concerned cities in geography and are easily affected by nonbordering regions in a mutual manner. Therefore, simple binary geographic unit matrix is not used as the spatial weight matrix in the paper. Besides, we take the 
reciprocal of distances between different cities as the element in distance weight matrix, expressed as

$$
W_{i j}= \begin{cases}0, & i=j \\ \frac{1}{\left(d_{i j}\right)^{2}}, & i \neq j\end{cases}
$$

where $d_{i j}$ is the greater-circle distance obtained on the basis of the latitude and longitude between city $i$ and city $j$. $W_{i j}$ considers the relation of all cities, and it allows the examination of all interactions in whole territory.

\section{Analysis and Discussion}

4.1. Estimation Results for the Whole Sample. In the application of SDM, we firstly investigate spatial dependence. From the results, the global Moran's I index of $\ln U S_{i, t}$ is 0.202 , inconsistent with the original hypothesis at $1 \%$ significance level, indicating that it is suggested to apply the maximum likelihood method to selecting the spatial econometric model for statistical verification. The LR test and the Wald test show that the SDM cannot degenerate into the SLM or the SEM. The Hausman test result shows that, under $1 \%$ significance level, it is suggested to select the fixed effect model of SDM. After comprehensively analyzing the R_squared, the natural $\log$-likelihood function value $\log \mathrm{L}$, and the joint significance of LR test (space fixed and time fixed), SDM is more reasonable under the fixed effect of space-time. Similar to the above steps for selecting a proper econometric model, we investigate that the SDM is more reasonable under the random effect when the dependent variable is population density. Hence, we choose the results of the above two models for analysis, and Table 3 lists various model test results.

As can be seen in Table 3, the coefficients of land finance and financial development on urban sprawl are positive and significant, indicating that land finance and financial development accelerated urban sprawl during 2012-2017. By observing the results of two different dependent variables, we find that the signs of most coefficients are opposite, indicating that population density can be used as a counterindicator of urban sprawl to some extent. However, the coefficients of land finance and financial development are not significantly associated with population density, indicating that it is not satisfactory to use population density as a traditional counter-indicator of urban sprawl at the national level. Moreover, the coefficient of the interaction between land finance and financial development on urban sprawl is negative and significant, indicating that land finance and financial development had a substitution effect on influencing urban sprawl in China. Furthermore, the coefficients of control variables are not significantly associated with urban sprawl, implying the core role of land finance and financial development influence urban sprawl when compared with other driving forces. Besides, the spatial coefficients $(\rho)$ also exhibit an obvious significance, strongly proving urban sprawl's spatial dependence at the national level.

Considering spatial autocorrelation, it is impossible for the regression coefficients of independent variables to reflect the marginal effects, or for the coefficients of the spatial lags of independent variables to reflect the spatial spillover effect in an accurate manner. However, the impacts of land finance and financial development and their spatial spillover effect on urban sprawl at the national level are quantified by virtue of direct effect and indirect effect as well as total effect which are obtained from regression coefficients of SDM.

Table 4 shows the decomposition estimates of the direct effect, indirect effect, and total effect calculated according to (7)-(9) as well as the regression coefficients of SDM in Table 3. The respective direct effect of land finance, financial development, and their interaction on urban sprawl is 0.354 , 0.261 , and -0.061 with a significant level of $5 \%$, while the indirect effects of land finance, financial development, and their interaction on urban sprawl are $0.237,0.258$, and 0.044 without passing the significant test, respectively. These results show that land finance, financial development, and their interaction have significant direct effects on the urban sprawl of local cities, but the effect on the urban sprawl of surrounding cities is not significant. Comparing the total effects, we investigate that the coefficients of land finance, financial development, and their interaction on urban sprawl and population density are opposite. It indicates that population density can be used as a counter-indicator of urban sprawl to some extent once again. Land finance and financial development accelerated urban sprawl during 2012-2017, while they had a substitution effect on influencing urban sprawl at the national level.

4.2. Estimation Results for the Subregional Sample. China is a big country with vast territory and land area. Therefore, the impact of land finance and financial development on urban sprawl in different regions varies greatly. In order to take full account of the differences in urban sprawl across regions, the regression is reestimated using the subsamples of three geographical regions (namely, the eastern region, central region, and western region) proposed by the National Bureau of Statistics (NBS). The results for regression in these three regions are reported in Table 5.

Generally, the results of three different regions are not all consistent with the results of the whole sample, which means the spatial heterogeneity of different regions is significant. The estimation results of land finance, financial development, and their interaction in the central region have similarity and more significant estimation results using the whole sample. However, the estimation results of land finance, financial development, and their interaction in the western region have similar estimation results using the whole sample, but not significant statistically. One possible reason is that the amount of land finance and financial development in the western region was relatively low compared to the central region. Furthermore, the estimation results of land finance, financial development, and their interaction in the eastern region have opposite estimation results using the whole sample but not significant statistically. One possible reason is that China's national government's control over the indicators of urban construction land compared to the other two regions restricted the urban sprawl in the eastern region. In addition, the spatial coefficients $(\rho)$ are also exhibit an 
TABLE 3: The results for the whole sample.

\begin{tabular}{|c|c|c|c|c|c|c|c|c|}
\hline \multirow{4}{*}{$\begin{array}{l}\text { Variables } \\
\text { Constant }\end{array}$} & \multicolumn{8}{|c|}{ Dependent Variable } \\
\hline & \multicolumn{4}{|c|}{ Urban Sprawl } & \multicolumn{4}{|c|}{ Population Density } \\
\hline & $-4.362 * * *$ & & & & $8.983 * * *$ & & & \\
\hline & $(-3.399)$ & & & & $(7.703)$ & & & \\
\hline \multirow{2}{*}{$\ln L F_{\mathrm{i}, \mathrm{t}-1}$} & $0.419 * * *$ & $0.318 * *$ & $0.471 * *$ & $0.342 * *$ & -0.075 & 0.063 & -0.113 & 0.033 \\
\hline & $(2.209)$ & $(2.075)$ & $(2.502)$ & $(2.234)$ & $(-0.444)$ & $(0.848)$ & $(-0.679)$ & $(0.462)$ \\
\hline \multirow{2}{*}{$\ln F D_{\mathrm{i}, \mathrm{t}-1}$} & 0.114 & $0.281 * *$ & 0.137 & $0.254 * *$ & 0.084 & 0.008 & 0.070 & 0.038 \\
\hline & $(0.859)$ & $(2.372)$ & $(1.041)$ & $(2.138)$ & $(0.711)$ & $(0.137)$ & $(0.601)$ & $(0.685)$ \\
\hline $\ln L F_{\mathrm{i}, \mathrm{t}-1} *$ & $-0.061 *$ & $-0.054 *$ & $-0.070 * *$ & $-0.059 * *$ & 0.002 & -0.011 & 0.009 & -0.005 \\
\hline $\ln F D_{\mathrm{i}, \mathrm{t}-1}$ & $(-1.723)$ & $(-1.884)$ & $(-1.997)$ & $(-2.050)$ & $(0.060)$ & $(-0.779)$ & $(0.283)$ & $(-0.401)$ \\
\hline \multirow{2}{*}{$\ln H C_{\mathrm{i}, \mathrm{t}-1}$} & $-0.042 * * *$ & -0.002 & $-0.044 * * *$ & -0.006 & $0.056 * * *$ & -0.001 & $0.055 * * *$ & 0.001 \\
\hline & $(-4.565)$ & $(-0.266)$ & $(-4.580)$ & $(-0.628)$ & $(6.893)$ & $(-0.158)$ & $(6.531)$ & $(0.135)$ \\
\hline \multirow{2}{*}{$\ln G D P_{\mathrm{i}, \mathrm{t}-1}$} & -0.017 & -0.016 & -0.016 & -0.034 & 0.002 & -0.023 & 0.002 & -0.007 \\
\hline & $(-0.839)$ & $(-0.672)$ & $(-0.793)$ & $(-1.357)$ & $(0.092)$ & $(-1.943)$ & $(0.137)$ & $(-0.570)$ \\
\hline \multirow{2}{*}{$\ln F E_{\mathrm{i}, \mathrm{t}-1}$} & 0.003 & 0.012 & -0.004 & -0.002 & 0.057 & -0.001 & $0.064 * * *$ & 0.014 \\
\hline & $(0.110)$ & $(0.525)$ & $(-0.156)$ & $(-0.072)$ & $(2.322)$ & $(-0.087)$ & $(2.625)$ & $(1.321)$ \\
\hline \multirow{2}{*}{$\ln E D U_{\mathrm{i}, \mathrm{t}-1}$} & 0.042 & 0.009 & 0.043 & 0.015 & $-0.104 * * *$ & -0.015 & $-0.105 * * *$ & -0.021 \\
\hline & (1.428) & $(0.412)$ & $(1.488)$ & $(0.684)$ & $(-4.034)$ & $(-1.402)$ & $(-4.079)$ & $(-1.942)$ \\
\hline \multirow{2}{*}{$\ln H O S_{\mathrm{i}, \mathrm{t}-1}$} & $-0.130 * * *$ & -0.004 & $-0.139 * * *$ & -0.009 & $0.139 * * *$ & $0.022 * *$ & $0.147 * * *$ & $0.025 * *$ \\
\hline & $(-6.327)$ & $(-0.203)$ & $(-6.801)$ & $(-0.427)$ & $(7.612)$ & $(2.184)$ & $(8.093)$ & $(2.536)$ \\
\hline \multirow{2}{*}{$\ln G D_{\mathrm{i}, \mathrm{t}-1}$} & -0.028 & -0.011 & -0.025 & -0.011 & 0.007 & 0.007 & 0.006 & 0.007 \\
\hline & $(-1.421)$ & $(-0.767)$ & $(-1.290)$ & $(-0.740)$ & $(0.433)$ & $(1.060)$ & $(0.360)$ & (1.018) \\
\hline \multirow{2}{*}{$W * \ln L F_{\mathrm{i}, \mathrm{t}-1}$} & 0.387 & 0.119 & $0.492 *$ & 0.180 & -0.360 & 0.040 & $-0.436 *$ & -0.036 \\
\hline & (1.433) & $(0.585)$ & $(1.836)$ & $(0.878)$ & $(-1.501)$ & $(0.408)$ & $(-1.831)$ & $(-0.377)$ \\
\hline \multirow{2}{*}{$W * \ln F D_{\mathrm{i}, \mathrm{t}-1}$} & $0.444 * *$ & $0.265 *$ & $0.485 * *$ & 0.208 & $-0.452 * * *$ & $-0.144 * *$ & $-0.476 * * *$ & -0.081 \\
\hline & $(2.352)$ & $(1.766)$ & $(2.591)$ & (1.375) & $(-2.700)$ & $(-1.998)$ & $(-2.863)$ & $(-1.142)$ \\
\hline$W * \ln L F_{\mathrm{i}, \mathrm{t}-1} *$ & -0.082 & -0.022 & $-0.100 * *$ & -0.034 & $0.081 *$ & -0.007 & $0.095 * *$ & 0.007 \\
\hline $\ln F D_{\mathrm{i}, \mathrm{t}-\mathrm{l}}$ & $(-1.631)$ & $(-0.565)$ & $(-2.001)$ & $(-0.882)$ & $(1.819)$ & $(-0.406)$ & $(2.134)$ & $(0.394)$ \\
\hline \multirow{2}{*}{$W * \ln H C_{\mathrm{i}, \mathrm{t}-1}$} & 0.009 & 0.018 & 0.005 & 0.006 & $-0.027 * *$ & -0.002 & $-0.028 * *$ & 0.002 \\
\hline & $(0.700)$ & $(1.624)$ & $(0.332)$ & $(0.449)$ & $(-2.414)$ & $(-0.357)$ & $(-2.205)$ & $(0.280)$ \\
\hline \multirow{2}{*}{$W * \ln G D P_{\mathrm{i}, \mathrm{t}-1}$} & 0.042 & $0.120 * * *$ & 0.044 & 0.039 & -0.022 & $-0.070 * * *$ & -0.020 & 0.003 \\
\hline & $(1.437)$ & (3.358) & $(1.502)$ & $(0.924)$ & $(-0.833)$ & $(-4.042)$ & $(-0.782)$ & $(0.173)$ \\
\hline \multirow{2}{*}{$W * \ln F E_{\mathrm{i}, \mathrm{t}-1}$} & $0.078 *$ & $0.065 *$ & 0.062 & 0.026 & -0.059 & $-0.045 * * *$ & -0.038 & -0.004 \\
\hline & (1.929) & $(1.821)$ & (1.508) & $(0.703)$ & $(-1.626)$ & $(-2.645)$ & $(-1.035)$ & $(-0.224)$ \\
\hline \multirow{2}{*}{$W * \ln E D U_{\mathrm{i}, \mathrm{t}-1}$} & -0.040 & -0.006 & -0.033 & 0.021 & 0.075 & 0.019 & $0.064 *$ & -0.004 \\
\hline & $(-0.975)$ & $(-0.170)$ & $(-0.810)$ & $(0.557)$ & $(2.084)$ & $(1.080)$ & $(1.767)$ & $(-0.247)$ \\
\hline \multirow{2}{*}{$W * \ln H O S_{\mathrm{i}, \mathrm{t}-1}$} & $0.082 * * *$ & -0.022 & $0.054 *$ & -0.048 & $-0.135 * * *$ & $-0.034 *$ & $-0.109 * * *$ & -0.008 \\
\hline & $(2.635)$ & $(-0.591)$ & (1.709) & $(-1.260)$ & $(-4.874)$ & $(-1.885)$ & $(-3.898)$ & $(-0.471)$ \\
\hline \multirow{2}{*}{$W * \ln G D_{\mathrm{i}, \mathrm{t}-1}$} & 0.015 & 0.022 & 0.014 & 0.020 & 0.004 & $-0.023 * *$ & 0.007 & $-0.020 *$ \\
\hline & $(0.474)$ & $(0.972)$ & $(0.453)$ & $(0.880)$ & $(0.142)$ & $(-2.077)$ & $(0.251)$ & $(-1.845)$ \\
\hline \multirow{2}{*}{$\rho$} & $0.167 * * *$ & $0.108 * * *$ & $0.135 * * *$ & $0.101 * * *$ & $0.223 * * *$ & $0.250 * * *$ & $0.198 * * *$ & $0.170 * * *$ \\
\hline & $(6.347)$ & (3.983) & $(5.044)$ & (3.697) & $(8.762)$ & $(9.928)$ & $(7.640)$ & $(6.394)$ \\
\hline Space-fixed & No & Yes & No & Yes & No & Yes & No & Yes \\
\hline Time-fixed & No & No & Yes & Yes & No & No & Yes & Yes \\
\hline
\end{tabular}


TABLE 3: Continued.

\begin{tabular}{|c|c|c|c|c|c|c|c|c|}
\hline \multirow{3}{*}{$\begin{array}{l}\text { Variables } \\
\text { R-squared }\end{array}$} & \multicolumn{8}{|c|}{ Dependent Variable } \\
\hline & \multicolumn{4}{|c|}{ Urban Sprawl } & \multicolumn{4}{|c|}{ Population Density } \\
\hline & 0.176 & 0.788 & 0.194 & 0.790 & 0.229 & 0.942 & 0.246 & 0.945 \\
\hline $\begin{array}{l}\text { Log-likeli } \\
\text {-hood }\end{array}$ & -360.299 & 790.660 & -338.309 & 815.560 & -164.947 & 2025.206 & -142.850 & 2093.934 \\
\hline Moran's I & \multicolumn{4}{|c|}{$0.162 * * *$} & \multicolumn{4}{|c|}{$0.210 * * *$} \\
\hline $\begin{array}{l}\text { LR_joint_- } \\
\text { space fixed }\end{array}$ & \multicolumn{4}{|c|}{$2372.376 * * *$} & \multicolumn{4}{|c|}{$4577.916 * * *$} \\
\hline $\begin{array}{l}\text { LR_joint_ } \\
\text { time fixed }\end{array}$ & \multicolumn{4}{|c|}{$82.005 * * *$} & \multicolumn{4}{|c|}{$367.134 * * *$} \\
\hline $\begin{array}{l}\text { Wald_ } \\
\text { spatial_lag }\end{array}$ & \multicolumn{4}{|c|}{12.065} & \multicolumn{4}{|c|}{11.662} \\
\hline $\begin{array}{l}\text { LR_spatial } \\
\text { _lag }\end{array}$ & \multicolumn{4}{|c|}{12.036} & \multicolumn{4}{|c|}{11.612} \\
\hline $\begin{array}{l}\text { Wald_ } \\
\text { spatial_error }\end{array}$ & \multicolumn{4}{|c|}{12.903} & \multicolumn{4}{|c|}{10.763} \\
\hline $\begin{array}{l}\text { LR_spatial_ } \\
\text { error }\end{array}$ & \multicolumn{4}{|c|}{12.860} & \multicolumn{4}{|c|}{10.687} \\
\hline Hauman test & \multicolumn{4}{|c|}{$272.140 * * *$} & \multicolumn{4}{|c|}{11.315} \\
\hline Obs & 1710 & 1710 & 1710 & 1710 & 1710 & 1710 & 1710 & 1710 \\
\hline
\end{tabular}

Notes: the $\mathrm{t}$-statistical data is provided in the parentheses; ${ }^{* * *},{ }^{* *}$, and ${ }^{*}$ refer to the statistical significance level $(1 \%, 5 \%$, and $10 \%$, respectively).

TABLE 4: The direct, indirect, and total effects of the whole sample.

\begin{tabular}{|c|c|c|c|c|c|c|}
\hline \multirow{2}{*}{ Variables } & \multicolumn{3}{|c|}{ Urban Sprawl } & \multicolumn{3}{|c|}{ Population Density } \\
\hline & Direct Effect & Indirect Effect & Total Effect & Direct Effect & Indirect Effect & Total Effect \\
\hline \multirow{2}{*}{$\ln L F_{\mathrm{i}, \mathrm{t}-1}$} & $0.354 * *$ & 0.237 & $0.591 * *$ & -0.104 & -0.451 & -0.555 \\
\hline & $(2.305)$ & $(1.077)$ & $(2.165)$ & $(-0.606)$ & $(-1.522)$ & $(-1.472)$ \\
\hline \multirow{2}{*}{$\ln F D_{\mathrm{i}, \mathrm{t}-1}$} & $0.261 * *$ & 0.258 & $0.519 * *$ & 0.049 & $-0.521 * *$ & $-0.472 *$ \\
\hline & $(2.222)$ & $(1.589)$ & $(2.675)$ & $(0.410)$ & $(-2.514)$ & $(-1.789)$ \\
\hline $\ln L F_{\mathrm{i}, \mathrm{t}-1} *$ & $-0.061 * *$ & -0.044 & $-0.106 * *$ & 0.008 & $0.098 *$ & 0.106 \\
\hline $\ln F D_{\mathrm{i}, \mathrm{t}-1}$ & $(-2.125)$ & $(-1.066)$ & $(-2.051)$ & $(0.260)$ & $(1.771)$ & $(1.508)$ \\
\hline \multirow{2}{*}{$\ln H C_{\mathrm{i}, \mathrm{t}-1}$} & -0.006 & 0.006 & 0.001 & $0.055 * * *$ & -0.018 & $0.036 * *$ \\
\hline & $(-0.599)$ & $(0.410)$ & $(0.035)$ & $(7.232)$ & $(-1.369)$ & $(2.395)$ \\
\hline \multirow{2}{*}{$\ln G D P_{\mathrm{i}, \mathrm{t}-1}$} & -0.034 & 0.038 & 0.004 & 0.001 & -0.027 & -0.026 \\
\hline & $(-1.33)$ & $(0.844)$ & $(0.089)$ & $(0.045)$ & $(-0.856)$ & $(-0.732)$ \\
\hline \multirow{2}{*}{$\ln F E_{\mathrm{i}, \mathrm{t}-1}$} & -0.001 & 0.027 & 0.026 & $0.054 * *$ & -0.056 & -0.002 \\
\hline & $(-0.044)$ & $(0.671)$ & $(0.555)$ & $(2.258)$ & $(-1.316)$ & $(-0.046)$ \\
\hline \multirow{2}{*}{$\ln E D U_{\mathrm{i}, \mathrm{t}-1}$} & 0.017 & 0.025 & 0.042 & $-0.101 * * *$ & 0.065 & -0.037 \\
\hline & $(0.771)$ & $(0.627)$ & $(0.932)$ & $(-3.947)$ & $(1.581)$ & $(-0.869)$ \\
\hline \multirow{2}{*}{$\ln H O S_{\mathrm{i}, \mathrm{t}-1}$} & -0.011 & -0.054 & -0.065 & $0.130 * * *$ & $-0.126 * * *$ & 0.005 \\
\hline & $(-0.512)$ & $(-1.327)$ & $(-1.387)$ & $(7.246)$ & $(-3.807)$ & $(0.120)$ \\
\hline \multirow{2}{*}{$\ln G D_{\mathrm{i}, \mathrm{t}-1}$} & -0.010 & 0.021 & 0.011 & 0.007 & 0.006 & 0.013 \\
\hline & $(-0.724)$ & $(0.877)$ & $(0.376)$ & $(0.376)$ & $(0.188)$ & $(0.321)$ \\
\hline
\end{tabular}

Notes: the t-statistical data are provided in the parentheses; ${ }^{* * *},{ }^{* *}$, and ${ }^{*}$ refer to the statistical significance level (1\%, $5 \%$, and $10 \%$, respectively).

obvious significance, strongly proving the spatial dependence of urban sprawl among different regions.

The decomposition estimates of the direct effect, indirect effect, and total effect of the eastern region are listed in Table 6. As shown in Table 6, all the coefficients of land finance, financial development, and their interaction are not significant statistically, implying the driving mechanism of urban sprawl relying on land finance and financial development has lost momentum for the limitation of urban construction land supply, and using compact urban development to replace urban sprawl may become the future direction of the eastern region in the long run.

The decomposition estimates of the direct effect, indirect effect, and total effect of the central region are listed in 
TABLE 5: The results of the subregional sample.

\begin{tabular}{|c|c|c|c|c|c|c|}
\hline \multirow{2}{*}{ Variables } & \multicolumn{2}{|c|}{ Eastern } & \multicolumn{2}{|c|}{ Central } & \multicolumn{2}{|c|}{ Western } \\
\hline & Urban Sprawl & Population Density & Urban Sprawl & Population Density & Urban Sprawl & Population Density \\
\hline \multirow{2}{*}{$\ln L F_{\mathrm{i}, \mathrm{t}-1}$} & -0.116 & 0.079 & $1.273 * * *$ & -0.101 & 0.125 & -0.097 \\
\hline & $(-0.917)$ & $(0.772)$ & $(3.283)$ & $(-0.754)$ & $(0.959)$ & $(-0.857)$ \\
\hline \multirow{2}{*}{$\ln F D_{\mathrm{i}, \mathrm{t}-1}$} & -0.024 & 0.075 & $1.063 * * *$ & -0.122 & 0.045 & -0.055 \\
\hline & $(-0.236)$ & $(0.905)$ & $(3.402)$ & $(-1.138)$ & $(0.463)$ & $(-0.657)$ \\
\hline \multirow{2}{*}{$\ln L F_{\mathrm{i}, \mathrm{t}-1} * \ln F D_{\mathrm{i}, \mathrm{t}-1}$} & 0.022 & -0.017 & $-0.223 * * *$ & 0.020 & -0.029 & 0.024 \\
\hline & $(0.929)$ & $(-0.884)$ & $(-3.006)$ & $(0.795)$ & $(-1.187)$ & $(1.096)$ \\
\hline \multirow{2}{*}{$\ln H C_{\mathrm{i}, \mathrm{t}-1}$} & -0.008 & 0.001 & -0.022 & 0.004 & 0.013 & 0.001 \\
\hline & $(-1.076)$ & $(0.155)$ & $(-1.055)$ & $(0.581)$ & $(1.619)$ & $(0.109)$ \\
\hline \multirow{2}{*}{$\ln G D P_{\mathrm{i}, \mathrm{t}-1}$} & -0.008 & 0.013 & -0.060 & -0.006 & 0.001 & -0.044 \\
\hline & $(-0.48)$ & $(0.956)$ & $(-1.154)$ & $(-0.360)$ & $(0.032)$ & $(-1.359)$ \\
\hline \multirow{2}{*}{$\ln F E_{\mathrm{i}, \mathrm{t}-1}$} & 0.016 & 0.010 & -0.016 & 0.020 & -0.032 & 0.020 \\
\hline & $(0.816)$ & $(0.621)$ & $(-0.270)$ & $(0.999)$ & $(-1.436)$ & $(1.041)$ \\
\hline \multirow{2}{*}{$\ln E D U_{\mathrm{i}, \mathrm{t}-1}$} & 0.013 & -0.026 & 0.034 & $-0.029 *$ & 0.000 & -0.004 \\
\hline & $(0.642)$ & $(-1.499)$ & $(0.747)$ & $(-1.826)$ & $(-0.004)$ & $(-0.223)$ \\
\hline \multirow{2}{*}{$\ln H O S_{\mathrm{i}, \mathrm{t}-1}$} & -0.024 & 0.000 & -0.081 & $0.071 * * *$ & 0.003 & $0.026 *$ \\
\hline & $(-1.307)$ & $(-0.017)$ & $(-1.322)$ & $(3.367)$ & $(0.182)$ & (1.909) \\
\hline \multirow{2}{*}{$\ln G D_{\mathrm{i}, \mathrm{t}-1}$} & $0.033 *$ & -0.019 & -0.025 & 0.004 & -0.012 & $0.014 *$ \\
\hline & $(1.777)$ & $(-1.273)$ & $(-0.489)$ & $(0.227)$ & $(-1.347)$ & $(1.842)$ \\
\hline \multirow{2}{*}{$W * \ln L F_{\mathrm{i}, \mathrm{t}-1}$} & 0.128 & -0.151 & 0.395 & 0.058 & 0.195 & -0.019 \\
\hline & $(0.673)$ & $(-0.978)$ & $(0.760)$ & $(0.325)$ & $(1.216)$ & $(-0.136)$ \\
\hline \multirow{2}{*}{$W * \ln F D_{\mathrm{i}, \mathrm{t}-1}$} & -0.054 & -0.099 & 0.437 & 0.010 & 0.276 & -0.109 \\
\hline & $(-0.368)$ & $(-0.834)$ & $(1.052)$ & $(0.074)$ & $(2.424)$ & $(-1.101)$ \\
\hline$W * \ln L F_{\mathrm{i}, \mathrm{t}-1} *$ & -0.025 & 0.032 & -0.071 & -0.016 & -0.038 & 0.005 \\
\hline $\ln F D_{\mathrm{i}, \mathrm{t}-1}$ & $(-0.698)$ & $(1.096)$ & $(-0.711)$ & $(-0.471)$ & $(-1.255)$ & $(0.178)$ \\
\hline \multirow{2}{*}{$W * \ln H C_{\mathrm{i}, \mathrm{t}-1}$} & -0.006 & 0.007 & 0.035 & 0.003 & -0.009 & 0.019 \\
\hline & $(-0.499)$ & $(0.735)$ & (1.129) & $(0.245)$ & $(-0.664)$ & $(1.727)$ \\
\hline \multirow{2}{*}{$W * \ln G D P_{\mathrm{i}, \mathrm{t}-1}$} & 0.028 & -0.037 & 0.056 & 0.024 & 0.006 & 0.077 \\
\hline & $(1.026)$ & $(-1.641)$ & $(0.538)$ & $(0.657)$ & $(0.132)$ & $(1.811)$ \\
\hline \multirow{2}{*}{$W * \ln F E_{\mathrm{i}, \mathrm{t}-1}$} & 0.009 & -0.019 & 0.012 & 0.053 & $0.066 * *$ & -0.032 \\
\hline & $(0.295)$ & $(-0.771)$ & $(0.121)$ & $(1.504)$ & $(2.097)$ & $(-1.157)$ \\
\hline \multirow{2}{*}{$W * \ln E D U_{\mathrm{i}, \mathrm{t}-1}$} & -0.023 & 0.039 & $0.260 * * *$ & $-0.081 * *$ & $-0.053 *$ & 0.021 \\
\hline & $(-0.763)$ & $(1.605)$ & $(2.709)$ & $(-2.449)$ & $(-1.763)$ & $(0.787)$ \\
\hline$W * \ln H O S_{i}$ & -0.024 & 0.038 & $-0.359 * * *$ & -0.015 & 0.028 & 0.005 \\
\hline$v_{i, t-1}$ & $(-0.784)$ & $(1.503)$ & $(-3.119)$ & $(-0.379)$ & $(0.958)$ & $(0.206)$ \\
\hline$W * \ln G D$ & 0.007 & -0.043 & 0.058 & $-0.090 * *$ & 0.012 & -0.002 \\
\hline 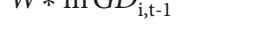 & $(0.181)$ & $(-1.391)$ & $(0.537)$ & $(-2.436)$ & $(0.907)$ & $(-0.203)$ \\
\hline$\rho$ & 0.008 & $0.108 * *$ & 0.065 & $0.110 * *$ & $0.189 * * *$ & $0.135 * * *$ \\
\hline$\beta$ & $(0.167)$ & $(2.445)$ & $(1.431)$ & $(2.458)$ & $(4.218)$ & $(2.941)$ \\
\hline Space-fixed & Yes & Yes & Yes & Yes & Yes & Yes \\
\hline Time-fixed & Yes & Yes & Yes & Yes & Yes & Yes \\
\hline R-squared & 0.934 & 0.955 & 0.685 & 0.948 & 0.922 & 0.941 \\
\hline Log-likelihood & 761.164 & 884.216 & 51.525 & 689.940 & 530.713 & 601.290 \\
\hline Moran's I & $0.195 * * *$ & $0.221 * * *$ & $0.057 *$ & 0.032 & $0.212 * * *$ & $0.221 * * *$ \\
\hline LR_joint_space fixed & $1502.513 * * *$ & $1729.845 * * *$ & $566.985 * * *$ & $1604.641 * * *$ & $1044.349 * * *$ & $1194.864 * * *$ \\
\hline LR_joint_time fixed & $84.622 * * *$ & $159.327 * * *$ & $11.915 *$ & $94.979 * * *$ & $81.177 * * *$ & $106.811 * * *$ \\
\hline Wald_spatial_lag & 12.395 & 12.931 & $19.640 * *$ & $15.045 *$ & $19.951 * *$ & $18.072 * *$ \\
\hline LR_spatial_lag & 12.277 & 12.801 & $19.498 * *$ & $14.919 *$ & $19.544 * *$ & $17.722 * *$ \\
\hline Wald_spatial_error & 12.424 & 12.544 & $20.434 * *$ & $15.505 *$ & $18.564 * *$ & $17.472 * *$ \\
\hline LR_spatial_error & 12.381 & 12.451 & $20.157 * *$ & $15.340 *$ & $18.161 * *$ & $17.116 * *$ \\
\hline Hauman test & $145.872 * * *$ & $153.106 * * *$ & $53.154 * * *$ & $144.955 * * *$ & $39.194 * * *$ & $135.500 * * *$ \\
\hline Obs & 606 & 606 & 600 & 600 & 504 & 504 \\
\hline
\end{tabular}

Notes: the t-statistical information is provided in the parentheses; ${ }^{* * *},{ }^{* *}$, and ${ }^{*}$ stand for the statistical significance level (1\%, $5 \%$, and $10 \%$, respectively). 
TABLE 6: The direct, indirect, and total effects of eastern regions.

\begin{tabular}{|c|c|c|c|c|c|c|}
\hline \multirow{2}{*}{ Variables } & \multicolumn{3}{|c|}{ Urban Sprawl } & \multicolumn{3}{|c|}{ Population Density } \\
\hline & Direct Effect & Indirect Effect & Total Effect & Direct Effect & Indirect Effect & Total Effect \\
\hline \multirow{2}{*}{$\ln L F_{\mathrm{i}, \mathrm{t}-1}$} & -0.112 & 0.124 & 0.012 & 0.073 & -0.150 & -0.077 \\
\hline & $(-0.901)$ & $(0.636)$ & $(0.053)$ & $(0.713)$ & $(-0.893)$ & $(-0.373)$ \\
\hline \multirow{2}{*}{$\ln F D_{\mathrm{i}, \mathrm{t}-1}$} & -0.020 & -0.059 & -0.078 & 0.073 & -0.095 & -0.022 \\
\hline & $(-0.198)$ & $(-0.396)$ & $(-0.481)$ & $(0.890)$ & $(-0.746)$ & $(-0.148)$ \\
\hline $\ln L F_{\mathrm{i}, \mathrm{t}-1} *$ & 0.021 & -0.024 & -0.003 & -0.016 & 0.031 & 0.015 \\
\hline $\ln F D_{\mathrm{i}, \mathrm{t}-1}$ & $(0.915)$ & $(-0.663)$ & $(-0.069)$ & $(-0.826)$ & $(1.001)$ & $(0.403)$ \\
\hline \multirow{2}{*}{$\ln H C_{\mathrm{i}, \mathrm{t}-1}$} & -0.008 & -0.006 & -0.015 & 0.001 & 0.009 & 0.010 \\
\hline & $(-1.117)$ & $(-0.549)$ & $(-1.215)$ & $(0.219)$ & $(0.814)$ & $(0.855)$ \\
\hline \multirow{2}{*}{$\ln G D P_{\mathrm{i}, \mathrm{t}-1}$} & -0.008 & 0.029 & 0.021 & 0.013 & -0.038 & -0.025 \\
\hline & $(-0.460)$ & $(1.075)$ & $(0.742)$ & $(0.955)$ & $(-1.534)$ & $(-0.914)$ \\
\hline \multirow{2}{*}{$\ln F E_{\mathrm{i}, \mathrm{t}-1}$} & 0.017 & 0.009 & 0.026 & 0.010 & -0.019 & -0.010 \\
\hline & $(0.833)$ & $(0.296)$ & $(0.768)$ & $(0.579)$ & $(-0.72)$ & $(-0.33)$ \\
\hline \multirow{2}{*}{$\ln E D U_{\mathrm{i}, \mathrm{t}-1}$} & 0.014 & -0.024 & -0.010 & -0.025 & 0.039 & 0.014 \\
\hline & $(0.65)$ & $(-0.802)$ & $(-0.292)$ & $(-1.459)$ & $(1.456)$ & $(0.447)$ \\
\hline \multirow{2}{*}{$\ln H O S_{\mathrm{i}, \mathrm{t}-1}$} & -0.024 & -0.025 & -0.049 & 0.001 & 0.040 & 0.041 \\
\hline & $(-1.366)$ & $(-0.821)$ & $(-1.479)$ & $(0.07)$ & (1.561) & (1.405) \\
\hline \multirow{2}{*}{$\ln G D_{\mathrm{i}, \mathrm{t}-1}$} & $0.033 *$ & 0.008 & 0.042 & -0.021 & -0.050 & $-0.071 *$ \\
\hline & (1.757) & $(0.209)$ & $(0.911)$ & $(-1.393)$ & $(-1.483)$ & $(-1.795)$ \\
\hline
\end{tabular}

Notes: the t-statistical information is provided in the parentheses; ${ }^{* * *},{ }^{* *}$, and ${ }^{*}$ stand for the statistical significance level (1\%, $5 \%$, and $10 \%$, respectively).

TABLE 7: The direct, indirect, and total effects of the central region.

\begin{tabular}{|c|c|c|c|c|c|c|}
\hline \multirow{2}{*}{ Variables } & \multicolumn{3}{|c|}{ Urban Sprawl } & \multicolumn{3}{|c|}{ Population Density } \\
\hline & Direct Effect & Indirect Effect & Total Effect & Direct Effect & Indirect Effect & Total Effect \\
\hline \multirow{2}{*}{$\ln L F_{\mathrm{i}, \mathrm{t}-1}$} & $1.281 * * *$ & 0.493 & $1.774 * * *$ & -0.097 & 0.045 & -0.052 \\
\hline & $(3.305)$ & $(0.899)$ & $(2.661)$ & $(-0.722)$ & $(0.232)$ & $(-0.221)$ \\
\hline \multirow{2}{*}{$\ln F D_{\mathrm{i}, \mathrm{t}-1}$} & $1.073 * * *$ & 0.523 & $1.596 * * *$ & -0.119 & -0.009 & -0.127 \\
\hline & $(3.442)$ & $(1.220)$ & $(3.240)$ & $(-1.117)$ & $(-0.056)$ & $(-0.713)$ \\
\hline $\ln L F_{\mathrm{i}, \mathrm{t}-1} *$ & $-0.225 * * *$ & -0.088 & $-0.313 * *$ & 0.019 & -0.014 & 0.006 \\
\hline $\ln F D_{\mathrm{i}, \mathrm{t}-1}$ & $(-3.027)$ & $(-0.836)$ & $(-2.452)$ & $(0.757)$ & $(-0.369)$ & $(0.126)$ \\
\hline \multirow{2}{*}{$\ln H C_{\mathrm{i}, \mathrm{t}-1}$} & -0.021 & 0.037 & 0.016 & 0.004 & 0.003 & 0.008 \\
\hline & $(-0.965)$ & $(1.176)$ & $(0.424)$ & $(0.594)$ & $(0.299)$ & $(0.548)$ \\
\hline \multirow{2}{*}{$\ln G D P_{\mathrm{i}, \mathrm{t}-1}$} & -0.059 & 0.055 & -0.003 & -0.006 & 0.024 & 0.018 \\
\hline & $(-1.099)$ & $(0.499)$ & $(-0.027)$ & $(-0.319)$ & $(0.614)$ & $(0.405)$ \\
\hline \multirow{2}{*}{$\ln F E_{\mathrm{i}, \mathrm{t}-1}$} & -0.017 & 0.012 & -0.005 & 0.022 & 0.057 & $0.080 *$ \\
\hline & $(-0.291)$ & $(0.113)$ & $(-0.044)$ & $(1.128)$ & $(1.517)$ & $(1.776)$ \\
\hline \multirow{2}{*}{$\ln E D U_{\mathrm{i}, \mathrm{t}-1}$} & 0.041 & $0.278 * * *$ & $0.318 * * *$ & $-0.032 * *$ & $-0.091 * *$ & $-0.124 * * *$ \\
\hline & $(0.903)$ & $(2.767)$ & $(2.926)$ & $(-2.088)$ & $(-2.399)$ & $(-2.945)$ \\
\hline \multirow{2}{*}{$\ln H O S_{\mathrm{i}, \mathrm{t}-1}$} & -0.087 & $-0.383 * * *$ & $-0.469 * * *$ & $0.070 * * *$ & -0.007 & 0.063 \\
\hline & $(-1.400)$ & $(-3.065)$ & $(-3.221)$ & $(3.316)$ & $(-0.157)$ & (1.201) \\
\hline \multirow{2}{*}{$\ln G D_{\mathrm{i}, \mathrm{t}-1}$} & -0.024 & 0.066 & 0.042 & 0.001 & $-0.098 * *$ & $-0.097 * *$ \\
\hline & $(-0.447)$ & $(0.580)$ & $(0.324)$ & $(0.048)$ & $(-2.387)$ & $(-2.111)$ \\
\hline
\end{tabular}

Notes: the t-statistical information is provided in the parentheses; ${ }^{* * *},{ }^{* *}$, and ${ }^{*}$ stand for the denote statistical significance degree $(1 \%, 5 \%$, and $10 \%$, respectively).

Table 7. As is shown in Table 7, the coefficients of the direct and total effects of land finance, financial development, and their interaction have a significant correlation with urban sprawl, similar to the regression coefficients of SDM in Table 5. However, the coefficients of the indirect effect of land finance, financial development, and their interaction are not significant statistically, implying land finance and financial development have significant promoted urban sprawl in the central region and there is a substitute effect on the increase of urban sprawl in the central region. The spillover effect is relatively weak compared to the direct effect. 
TABLE 8: The direct, indirect, and total effects of the western region.

\begin{tabular}{|c|c|c|c|c|c|c|}
\hline \multirow{2}{*}{ Variables } & \multicolumn{3}{|c|}{ Urban Sprawl } & \multicolumn{3}{|c|}{ Population Density } \\
\hline & Direct Effect & Indirect Effect & Total Effect & Direct Effect & Indirect Effect & Total Effect \\
\hline \multirow{2}{*}{$\ln L F_{\mathrm{i}, \mathrm{t}-1}$} & 0.145 & 0.265 & $0.409 *$ & -0.093 & -0.031 & -0.124 \\
\hline & $(1.117)$ & $(1.455)$ & $(1.736)$ & $(-0.827)$ & $(-0.210)$ & $(-0.652)$ \\
\hline \multirow{2}{*}{$\ln F D_{\mathrm{i}, \mathrm{t}-1}$} & 0.069 & $0.335 * *$ & $0.404 * *$ & -0.056 & -0.126 & -0.183 \\
\hline & $(0.728)$ & $(2.499)$ & $(2.326)$ & $(-0.660)$ & $(-1.200)$ & $(-1.300)$ \\
\hline $\ln L F_{\mathrm{i}, \mathrm{t}-1} *$ & -0.033 & -0.053 & $-0.086 *$ & 0.023 & 0.008 & 0.031 \\
\hline $\ln F D_{\mathrm{i}, \mathrm{t}-1}$ & $(-1.355)$ & $(-1.521)$ & $(-1.903)$ & $(1.066)$ & $(0.283)$ & $(0.844)$ \\
\hline \multirow{2}{*}{$\ln H C_{\mathrm{i}, \mathrm{t}-1}$} & 0.012 & -0.007 & 0.005 & 0.002 & 0.021 & 0.023 \\
\hline & $(1.553)$ & $(-0.475)$ & $(0.277)$ & $(0.265)$ & $(1.600)$ & $(1.435)$ \\
\hline \multirow{2}{*}{$\ln G D P_{\mathrm{i}, \mathrm{t}-1}$} & 0.000 & 0.010 & 0.010 & -0.041 & $0.081 *$ & 0.039 \\
\hline & $(0.008)$ & $(0.174)$ & $(0.147)$ & $(-1.254)$ & $(1.736)$ & $(0.735)$ \\
\hline \multirow{2}{*}{$\ln F E_{\mathrm{i}, \mathrm{t}-1}$} & -0.027 & $0.069 *$ & 0.042 & 0.018 & -0.032 & -0.014 \\
\hline & $(-1.172)$ & $(1.809)$ & $(0.853)$ & $(0.886)$ & $(-1.056)$ & $(-0.365)$ \\
\hline \multirow{2}{*}{$\ln E D U_{\mathrm{i}, \mathrm{t}-1}$} & -0.004 & $-0.061 *$ & -0.065 & -0.003 & 0.022 & 0.019 \\
\hline & $(-0.193)$ & $(-1.737)$ & $(-1.490)$ & $(-0.146)$ & $(0.739)$ & $(0.531)$ \\
\hline \multirow{2}{*}{$\ln H O S_{\mathrm{i}, \mathrm{t}-1}$} & 0.004 & 0.033 & 0.037 & 0.026 & 0.011 & 0.037 \\
\hline & $(0.248)$ & $(0.899)$ & $(0.836)$ & (1.935) & $(0.387)$ & (1.095) \\
\hline \multirow{2}{*}{$\ln G D_{\mathrm{i}, \mathrm{t}-1}$} & -0.010 & 0.011 & 0.001 & 0.014 & -0.001 & 0.013 \\
\hline & $(-1.167)$ & $(0.735)$ & $(0.049)$ & $(1.804)$ & $(-0.084)$ & $(0.793)$ \\
\hline
\end{tabular}

Notes: the t-statistical information is provided in the parentheses; ${ }^{* * *},{ }^{* *}$, and ${ }^{*}$ represent the statistical significance degree (1\%, $5 \%$, and $10 \%$, respectively).

The decomposition estimates of the direct effect, indirect effect and total effect of the western region are listed in Table 8. As is shown in Table 8, the coefficients of the total effect of land finance, financial development, and their interaction have significant correlations with urban sprawl, which are similar to the coefficients of central regions in Table 5. However, the coefficients of the direct effect of land finance, financial development, and their interaction are not significant statistically. The coefficients of the indirect effect of land finance and the interaction between land finance and financial development are also not statistically significant, while the coefficients of the indirect effect of financial development have a positive and significant correlation with urban sprawl, implying that land finance and financial development have significantly promoted urban sprawl in the western region and they have substitute effects on urban sprawl in the western region on the whole; the direct effect is weak compared to the central region.

\section{Conclusions and Policy Implications}

With the panel data of 285 prefecture-level cities in China from 2011 to 2017, an index of urban sprawl is constructed and calculated in this paper by using two metrics (urban population sprawl and urban land sprawl) extracted from the NPP/VIIRS data and LandScan data. Through the application of SDM and unified analysis, the mechanisms as well as effects of land finance, financial development, and their interaction on the impact of urban sprawl are investigated. Three main conclusions can be drawn from the above analysis. First, during the investigation, the intensity of urban population sprawl and urban land sprawl has been enhanced; however, the upside-down between the inflow of migrants and the supply of urban construction land aggravates the intensity of urban sprawl. Second, the impact of land finance, financial development, and their interaction on urban sprawl varies from region to region. In the eastern region, all of the coefficients of land finance, financial development, and their interaction are not significant statistically, implying the driving mechanism of urban sprawl relying on land finance and financial development has lost momentum for the limitation of urban construction land supply. In the central and the western regions, land finance and financial development have significantly promoted urban sprawl. They have substitutes effect on the increase of urban sprawl. However, the direct, indirect, and total effects of land finance, financial development, and their interaction on urban sprawl in the western region are weak compared to the central region. Third, the spatial coefficients $(\rho)$ are also highly significant at the national and regional level, which is strong evidence of spatial dependence of urban sprawl.

The findings in the paper contribute to three important policy implications. First, urban population sprawl in the eastern region deserves more attention. Although the contraction of urban construction land had effectively reduced the speed of urban land sprawl, it also pushed up house prices significantly, forcing a large number of inflows to gather in the city fringes and the edge of metropolitan areas and eroding urban sustainable development ability in the long run. Limited to the supply of urban construction land, it should further improve the use efficiency of land to achieve a compact form. Second, it is required to pay much attention to preventing urban land sprawl in the central and western regions. In order to promote coordinated 
development among different regions, China's national government has relaxed the constraints on urban construction land in central regions and western regions; however, the continuous outflow of population and loosely land supply have accelerated the intensity of urban land sprawl. As a result, it is necessary for China's national government to make a further control about the total urban construction land amount as well as focus more on assessing urban planning so as to improve the binding force on these cities. What is more, local government shall reform the fiscal system so as to promote the urban development more rationally. Third, the imbalance of urban development policies in different regions shall be rethought. Policymakers usually take advantage of the surging city diseases in eastern regions to control the supply of urban construction land. However, urban land sprawl in central regions and western regions have not gained enough attention. Thus, the advantages and disadvantages of the imbalanced urban development policies shall be taken into a remarkable consideration to achieve a more balanced development policy.

Despite above-mentioned valuable insights, the paper also suffers three limitations, which should be studied in further research. The first is that the study only covers seven years due to data limitation. To confirm our findings, it is suggested to lengthen the time span to a longer period and use more information and data for comprehensive and thorough analysis. Second, in our study, urban sprawl is divided into two types based on the difference between population and land, and each type of urban sprawl is measured by the standard of population density. In further research, an expansion of the indicator system may be considered to obtain more guiding conclusions. Third, the SDM is adopted to do the empirical analysis in this paper, but spatiotemporal effect is ignored, so the results may have some deviations compared to the actual situation. To expand the research, dynamic SDM should be applied to an empirical study on the impact of land finance, financial development, and their interaction on urban sprawl in China as well as other developing countries which experience similar processes of urbanization and modernization.

\section{Data Availability}

The data used to support the findings of this study are available from the corresponding author upon request

\section{Conflicts of Interest}

The author declares that they have no conflicts of interest.

\section{Acknowledgments}

This research is supported by the National Natural Science Foundation of China (no. 71473057 and no. 71874042). Particularly, we would like to thank the experts who participated in the improvement of this paper. Any remaining errors are the responsibility of the authors.

\section{References}

[1] S. Hamidi, R. Ewing, I. Preuss, and A. Dodds, "Measuring sprawl and its impacts: an update," Journal of Planning Education and Research, vol. 35, no. 1, pp. 35-50, 2015.

[2] C. Zhang, C. Miao, W. Zhang, and X. Chen, "Spatiotemporal patterns of urban sprawl and its relationship with economic development in China during 1990-2010," Habitat International, vol. 79, pp. 51-60, 2018.

[3] S. Hamidi, R. Ewing, Z. Tatalovich, J. B. Grace, and D. Berrigan, "Associations between urban sprawl and life expectancy in the United States," International Journal of Environmental Research and Public Health, vol. 15, no. 5, p. 861, 2018.

[4] B. Wilson and A. Chakraborty, "The environmental impacts of sprawl: emergent themes from the past decade of planning research," Sustainability, vol. 5, no. 8, pp. 3302-3327, 2013.

[5] X. Deng, J. Huang, S. Rozelle, and E. Uchida, "Economic growth and the expansion of urban land in China," Urban Studies, vol. 47, no. 4, pp. 813-843, 2010.

[6] X. Y. Li, L. M. Yang, Y. X. Ren, H. Y. Li, and Z. M. Wang, "Impacts of urban sprawl on soil resources in the ChangchunJilin economic zone, China, 2000-2015," International Journal of Environmental Research and Public Health, vol. 15, no. 6, p. 1186, 2018.

[7] P. Monforte and M. A. Ragusa, "Evaluation of the air pollution in a Mediterranean region by the air quality index," Environmental Modeling \& Assessment, vol. 190, no. 11, p. 625, 2018.

[8] F. Famoso, J. Wilson, P. Monforte, R. Lanzafame, S. Brusca, and V. Lulla, "Measurement and modeling of ground-level ozone concentration in Catania, Italy using biophysical remote sensing and GIS," International Journal of Applied Engineering Research, vol. 12, no. 21, pp. 10551-10562, 2017.

[9] R. M. S. Costa and P. Pavone, "Diachronic biodiversity analysis of a metropolitan area in the Mediterranean region," Acta Horticulturae, vol. 1215, pp. 49-52, 2018.

[10] R. Costa and P. Pavone, "Invasive plants and natural habitats: the role of alien species in the urban vegetation," Acta Horticulturae, no. 1215 , pp. 57-60, 2018.

[11] G. Ferrauto, R. M. S. Costa, P. Pavone, and G. L. Cantarella, "Human impact assessment on the sicilian agroecosystems through the evaluation of Melliferous areas," Annali di Botanica, vol. 3, pp. 237-244, 2013.

[12] C. Barrington-Leigh and A. Millard-Ball, "A century of sprawl in the United States," Proceedings of the National Acadamy of Sciences of the United States of America, vol. 112, no. 27, pp. 82448249, 2015.

[13] W. Yue, Y. Liu, and P. Fan, "Measuring urban sprawl and its drivers in large Chinese cities: The case of Hangzhou," Land Use Policy, vol. 31, pp. 358-370, 2013.

[14] J. Y. Liu, J. Y. Zhan, and X. Z. Deng, "Spatio-temporal patterns and driving forces of urban land expansion in china during the economic reform era," Ambio: A Journal of the Human Environment, vol. 34, no. 6, pp. 450-455, 2005.

[15] G. Zhou and Y. He, "The influencing factors of urban land expansion in Changsha," Journal of Geographical Sciences, vol. 17, no. 4, pp. 487-499, 2007.

[16] Q. Ma, C. He, and J. Wu, "Behind the rapid expansion of urban impervious surfaces in China: Major influencing factors revealed by a hierarchical multiscale analysis," Land Use Policy, vol. 59, pp. 434-445, 2016.

[17] W. Kuang, J. Liu, J. Dong, W. Chi, and C. Zhang, "The rapid and massive urban and industrial land expansions in China between 
1990 and 2010: A CLUD-based analysis of their trajectories, patterns, and drivers," Landscape and Urban Planning, vol. 145, pp. 21-33, 2016.

[18] W. Kuang, W. Chi, D. Lu, and Y. Dou, "A comparative analysis of megacity expansions in China and the U.S.: Patterns, rates and driving forces," Landscape and Urban Planning, vol. 132, pp. 121-135, 2014.

[19] Y. Fang and A. Pal, "Drivers of urban sprawl in urbanizing China - a political ecology analysis," Environment and Urbanization, vol. 28, no. 2, pp. 599-616, 2016.

[20] T. Zhang, "Land market forces and government's role in sprawl. The case of China," Cities, vol. 17, no. 2, pp. 123-135, 2000.

[21] C. Kowalczyk, J. Kil, and K. Kurowska, "Dynamics of development of the largest cities - Evidence from Poland," Cities, vol. 89, pp. 26-34, 2019.

[22] W. Sun, W. Chen, and Z. Jin, "Spatial function regionalization based on an ecological-economic analysis in Wuxi City, China," Chinese Geographical Science, vol. 29, no. 2, pp. 352-362, 2019.

[23] Z. Liu, S. Liu, W. Qi, and H. Jin, "Urban sprawl among Chinese cities of different population sizes," Habitat International, vol. 79, pp. 89-98, 2018.

[24] W. Ma, G. Jiang, W. Li, and T. Zhou, "How do population decline, urban sprawl and industrial transformation impact land use change in rural residential areas? A comparative regional analysis at the peri-urban interface," Journal of Cleaner Production, vol. 205, pp. 76-85, 2018.

[25] W. Yue, L. Zhang, and Y. Liu, "Measuring sprawl in large Chinese cities along the Yangtze River via combined single and multidimensional metrics," Habitat International, vol. 57, pp. 43-52, 2016.

[26] R. M. Ryznar and T. W. Wagner, "Using remotely sensed imagery to detect urban change: Viewing detroit from space," Journal of the American Planning Association, vol. 67, no. 3, pp. 327-336, 2001.

[27] J. Luo, D. Yu, and M. Xin, "Modeling urban growth using GIS and remote sensing," GIScience \& Remote Sensing, vol. 45, no. 4, pp. 426-442, 2008.

[28] B. Bhatta, S. Saraswati, and D. Bandyopadhyay, "Quantifying the degree-of-freedom, degree-of-sprawl, and degree-of-goodness of urban growth from remote sensing data," Applied Geography, vol. 30, no. 1, pp. 96-111, 2010.

[29] L. Wang, C. Li, Q. Ying et al., "China's urban expansion from 1990 to 2010 determined with satellite remote sensing," Chinese Science Bulletin, vol. 57, no. 22, pp. 2802-2812, 2012.

[30] Q. Weng, "Remote sensing of impervious surfaces in the urban areas: requirements, methods, and trends," Remote Sensing of Environment, vol. 117, pp. 34-49, 2012.

[31] B. Gao, Q. Huang, C. He, Z. Sun, and D. Zhang, "How does sprawl differ across cities in China? A multi-scale investigation using nighttime light and census data," Landscape and Urban Planning, vol. 148, pp. 89-98, 2016.

[32] Z. Zhang, F. Liu, X. Zhao et al., "Urban expansion in China based on remote sensing technology: a review," Chinese Geographical Science, vol. 28, no. 5, pp. 727-743, 2018.

[33] L. Wang, H. Han, and S. Lai, "Do plans contain urban sprawl? A comparison of Beijing and Taipei," Habitat International, vol. 42, pp. 121-130, 2014.

[34] C. Zeng, Y. Liub, A. Steind, and L. Jiao, "Characterization and spatial modeling of urban sprawl in the Wuhan Metropolitan Area, China," International Journal of Applied Earth Observation and Geoinformation, vol. 34, no. 1, pp. 10-24, 2015.
[35] J. Qian, Y. Peng, C. Luo, C. Wu, and Q. Du, "Urban land expansion and sustainable land use policy in Shenzhen: A case study of China's rapid urbanization," Sustainability, vol. 8, no. 1, pp. 1-16, 2016.

[36] G. Jiang, W. Ma, Y. Qu, R. Zhang, and D. Zhou, "How does sprawl differ across urban built-up land types in China? A spatial-temporal analysis of the Beijing metropolitan area using granted land parcel data," Cities, vol. 58, pp. 1-9, 2016.

[37] L. Tian, B. Ge, and Y. Li, "Impacts of state-led and bottomup urbanization on land use change in the peri-urban areas of Shanghai: Planned growth or uncontrolled sprawl?" Cities, vol. 60, pp. 476-486, 2017.

[38] S. Q. Zhao, D. C. Zhou, C. Zhu et al., "Rates and patterns of urban expansion in China's 32 major cities over the past three decades," Landscape Ecology, vol. 30, no. 8, pp. 1541-1559, 2015.

[39] Q. Zhang and S. Su, "Determinants of urban expansion and their relative importance: A comparative analysis of 30 major metropolitans in China," Habitat International, vol. 58, pp. 89107, 2016.

[40] C. Ding and X. Zhao, "Land market, land development and urban spatial structure in Beijing," Land Use Policy, vol. 40, pp. 83-90, 2014.

[41] L. Ye and A. M. Wu, "Urbanization, land development, and land financing: Evidence from chinese cities," Journal of Urban Affairs, vol. 36, no. 1, pp. 354-368, 2014.

[42] Y. Liu, P. Fan, W. Yue, and Y. Song, "Impacts of land finance on urban sprawl in China: The case of Chongqing," Land Use Policy, vol. 72, pp. 420-432, 2018.

[43] G. Lin and F. Yi, "Urbanization of capital or capitalization on urban land? Land development and local public finance in urbanizing China," Urban Geography, vol. 32, no. 1, pp. 50-79, 2011.

[44] Y. D. Wei, H. Li, and W. Yue, "Urban land expansion and regional inequality in transitional China," Landscape and Urban Planning, vol. 163, pp. 17-31, 2017.

[45] A. Schneider, C. Chang, and K. Paulsen, "The changing spatial form of cities in Western China," Landscape and Urban Planning, vol. 135, pp. 40-61, 2015.

[46] B. N. Fallah, M. D. Partridge, and M. R. Olfert, "Urban sprawl and productivity: Evidence from US metropolitan areas," Papers in Regional Science, vol. 90, no. 3, pp. 451-472, 2011.

[47] J. P. Elhorst, "Specification and estimation of spatial panel data models," International Regional Science Review, vol. 26, no. 3, pp. 244-268, 2003.

[48] L. F. Lee and J. H. Yu, "Introduction to spatial econometrics," Geographical Analysis, vol. 42, no. 3, pp. 356-359, 2010.

[49] J. P. LeSage and Y. Sheng, "A spatial econometric panel data examination of endogenous versus exogenous interaction in Chinese province-level patenting," Journal of Geographical Systems, vol. 16, no. 3, pp. 233-262, 2014.

[50] L.-F. Lee and J. Yu, "Identification of spatial Durbin panel models," Journal of Applied Econometrics, vol. 31, no. 1, pp. 133162,2016

[51] J. P. Elhorst, "Applied spatial econometrics: Raising the bar," Spatial Economic Analysis, vol. 5, no. 1, pp. 9-28, 2010.

[52] J. P. Elhorst, "Dynamic spatial panels: Models, methods, and inferences," Journal of Geographical Systems, vol. 14, no. 1, pp. $5-28,2012$. 


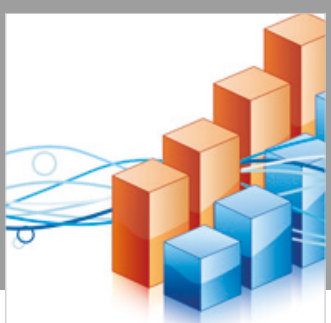

Advances in

Operations Research

\section{-n-m}
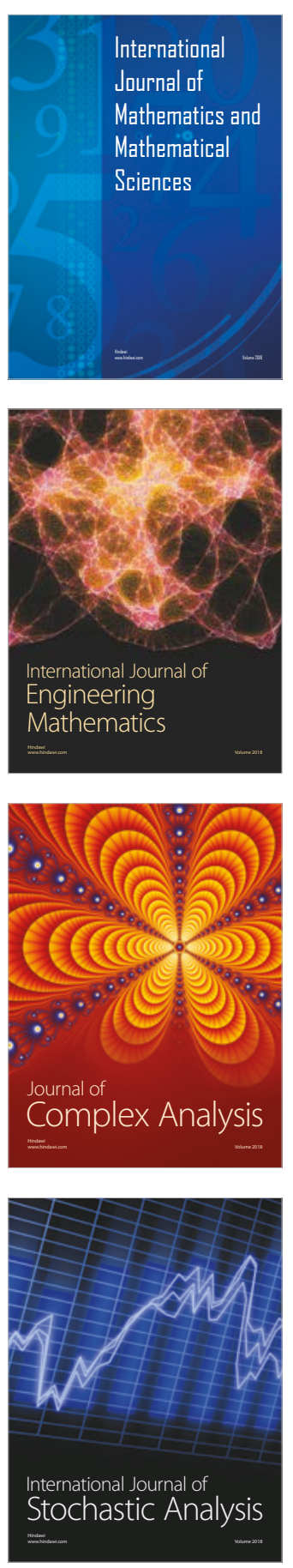
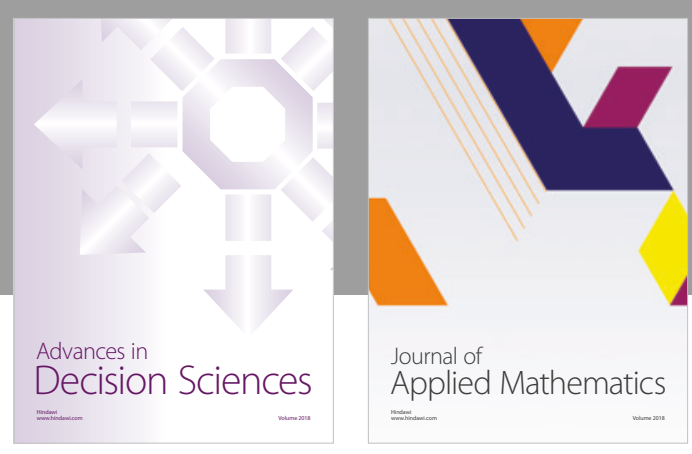

Journal of

Applied Mathematics
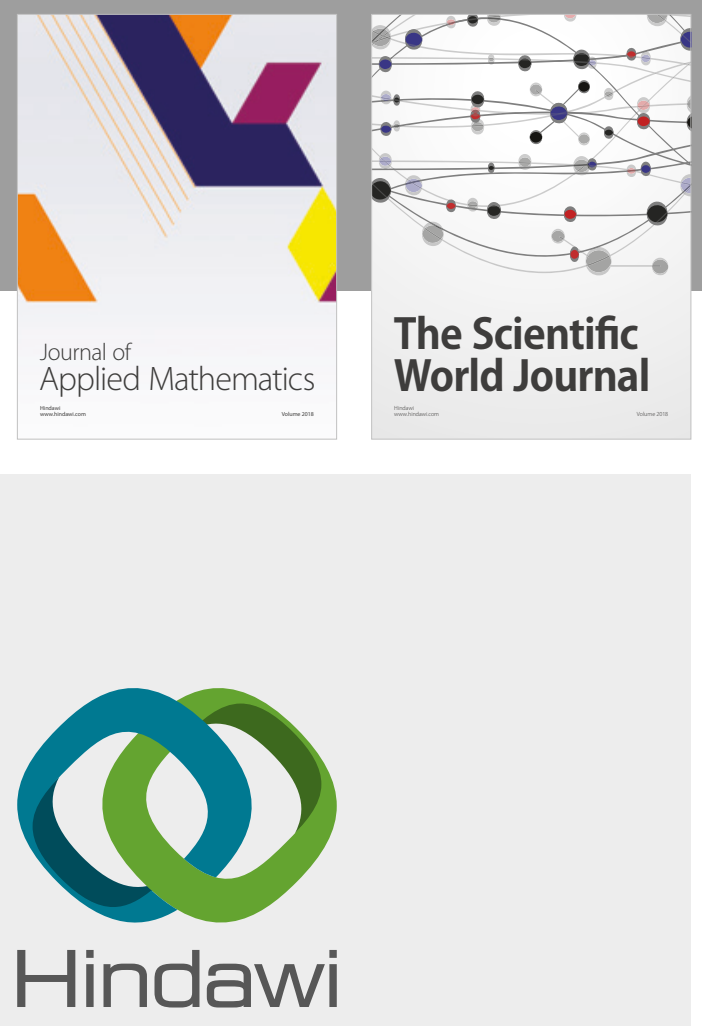

Submit your manuscripts at

www.hindawi.com

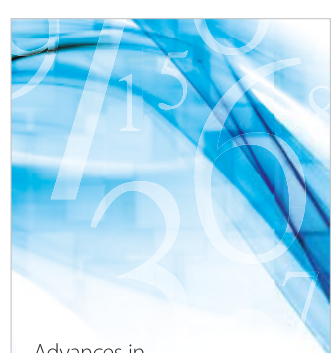

Advances in
Numerical Analysis
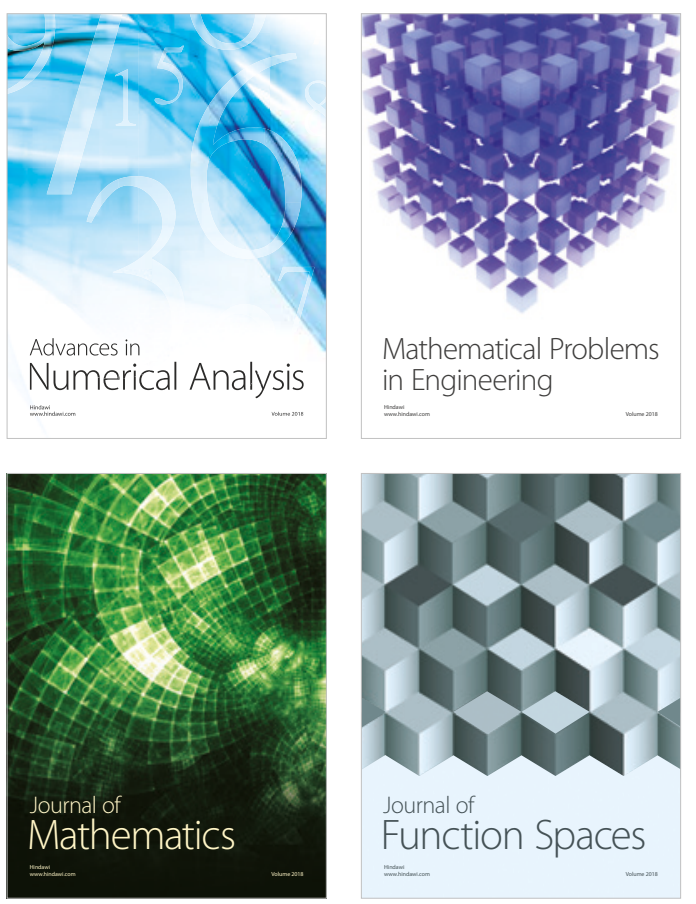

Mathematical Problems in Engineering

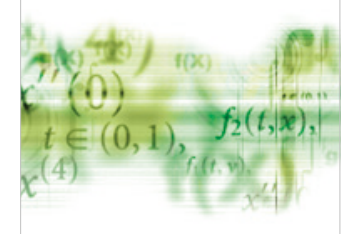

International Journal of

Differential Equations

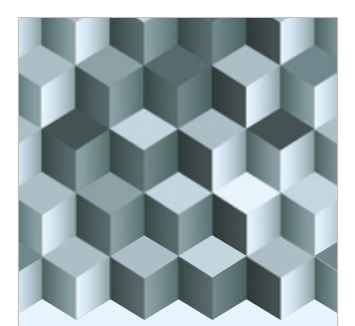

Journal of

Function Spaces

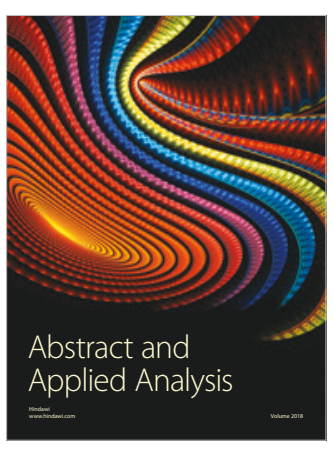

The Scientific

World Journal

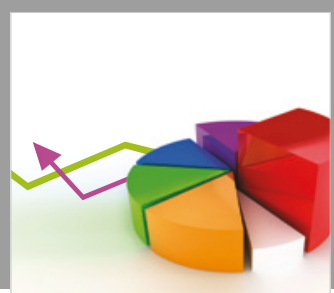

Journal of

Probability and Statistics
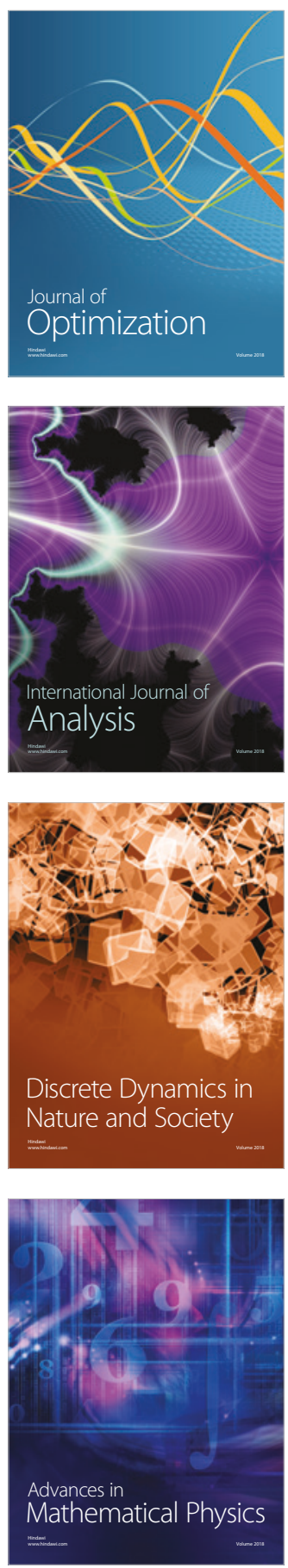